\title{
Late gadolinium enhancement is compatible with advanced age in hypertrophic cardiomyopathy: implications for risk stratification of sudden death
}

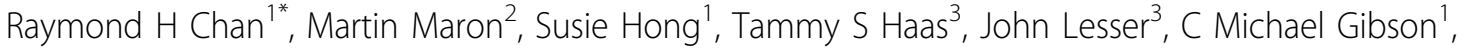 \\ Warren J Manning', Barry J Maron ${ }^{3}$, Evan Appelbaum ${ }^{1}$ \\ From 15th Annual SCMR Scientific Sessions \\ Orlando, FL, USA. 2-5 February 2012
}

\section{Background}

Hypertrophic cardiomyopathy (HCM) is most common in patients under 40 years and is associated with early sudden death, but HCM is increasingly recognized in elderly patients. We sought to characterize and identify features unique to elderly HCM patients when compared with youthful patients using CMR.

\section{Methods}

Cine CMR and late gadolinium enhancement (LGE) imaging were performed in $902 \mathrm{HCM}$ patients, including 202 young (15-35 years; mean $24.5 \pm 6.3$ years), and 143 elderly patients (age > 65 years; mean $70.9 \pm 4.8$ years). ).

\section{Results}

Elderly HCM patients had a lower proportion of males (53.8\% elderly vs $70.3 \%, p=0.002$ ). They had significantly lower left ventricular (LV) mass $(153 \pm 64$ g elderly vs $183 \pm 90 \mathrm{~g}, \mathrm{p}<0.001)$ and lower maximal LV wall thickness $(19 \pm 4 \mathrm{~mm}$ elderly vs $21 \pm 6 \mathrm{~mm}, \mathrm{p}<0.001)$. The most common maximal thickness segment in the elderly patients was in the basal anterior septum (35\% elderly vs $22 \%, \mathrm{p}=0.01$ ). Elderly patients were also more likely to have the thickest segment located within the septum (OR 1.74, 95\% C.I. 1.12 - 2.69, p=0.01). Elderly patients were far less likely to have massive hypertrophy (maximal wall thickness $>30 \mathrm{~mm}$ ) (OR 0.15, 95\% C.I. 0.03$0.64, \mathrm{p}=0.01$ ).

Elderly HCM patients had a smaller LV cavity size, with lower LV end-diastolic volume $(138 \pm 41 \mathrm{ml}$ elderly vs $165 \pm 45 \mathrm{ml}, \mathrm{p}<0.001)$ and smaller LV end-diastolic

\footnotetext{
${ }^{1}$ BIDMC, Boston, MA, USA
}

Full list of author information is available at the end of the article dimension $(52 \pm 7 \mathrm{~mm}$ elderly vs $54 \pm 7 \mathrm{~mm}, \mathrm{p}=0.05)$. The elderly patients had similar LV ejection fraction (LVEF) $(67 \pm 11 \%$ elderly vs $66 \pm 9 \%, \mathrm{p}>0.1)$ and similar rates of depressed $(<60 \%)$ LVEF ( $21 \%$ elderly vs $20 \%$, $\mathrm{p}=0.79$ ).

The prevalence of LGE (a marker of fibrosis) was similar in both groups (40.9\% elderly vs $43.5 \%, \mathrm{p}=0.64)$. When present, both LGE mass $(8.0 \pm 14.7 \mathrm{~g}$ elderly vs $9.6 \pm 15.1 \mathrm{~g}, \mathrm{p}>0.10)$ and percentage of LV with LGE $(8.6 \pm 10.4 \%$ elderly vs $6.9 \pm 8.3 \%, \mathrm{p}>0.10)$ were similar.

\section{Conclusions}

Substantial amounts of late gadolinium enhancement are compatible with normal longevity in many patients with hypertrophic cardiomyopathy. Presence of LGE may thus have different prognostic significance across the vast spectrum of HCM. This has potential implications for using LGE as a risk stratification tool for sudden death in HCM.

\section{Funding}

Nil.

\section{Author details}

'BIDMC, Boston, MA, USA. ${ }^{2}$ Tufts Medical Center, Boston, MA, USA.

${ }^{3}$ Minnesota Heart Institute Foundation, Minneapolis, MN, USA.

Published: 1 February 2012

doi:10.1186/1532-429X-14-S1-P156

Cite this article as: Chan et al:: Late gadolinium enhancement is compatible with advanced age in hypertrophic cardiomyopathy: implications for risk stratification of sudden death. Journal of

Cardiovascular Magnetic Resonance 2012 14(Suppl 1):P156. 